\title{
Deflection Analysis and Iterative Solution Method of Slender Telescopic Booms
}

\author{
Xuyang Cao, Zhenhua Gu* and Haojie Yu \\ School of Mechanical Engineering, Dalian University of Technology, 116024 Dalian, China \\ *Corresponding author
}

\begin{abstract}
In order to analyze accurately the deformation of the telescopic boom in the case of large deformation, an initial deflection curve can be get according to the nonlinear bending differential equation and calculation method. The retraction amount in initial axial direction of the boom and the second-order bending moment can be get after counting process with the initial deflection curve. Then these data can be used to amend the bending moment in the nonlinear bending differential equation and so a more accurate deflection curve can be get. The deflection curves of a typical telescopic boom were calculated and the results were compared with the results obtained by the approximate calculation method. The results show that the calculation method proposed in this paper can obtain the deflection curve of the telescopic boom accurately under large deformation condition. The results obtained by using the traditional approximation of the calculation method are too large.
\end{abstract}

Keywords-telescopic boom; deflection curve; nonlinearity; numerical calculation

\section{INTRODUCTION}

Most of the large construction machinery (such as cranes and aerial vehicles) have many box-type telescopic boom structures. Telescopic arms are the main load-bearing parts of such machines. The structure with large slenderness ratio leads to obvious non-linear characteristics and its performance has an important impact on the safe operation of the whole machine ${ }^{[1]}$. As the result, bending analysis is an important part of its performance evaluation.

At present, the researches on flexing lines of telescopic arms are in the approximate equation of flexure of beam sections. Huiming Xie ${ }^{[2]}$ deduced the curve expression using the boundary condition of the beam; Wenjing Wang et al ${ }^{[3]}$. combined the elastic stability theory to analyze the boom system non-linearly. Casafont $M$ et al ${ }^{[4]}$. used the finite element model based on the uncoupled buckling mode constraint to derive the constraint applied to the finite element model from the generalized beam theory.

Based on the analysis of related literatures, at present, the non-linear factors are not accurately considered in the solution of flexural curves. This paper draws on and improves the research methods of predecessors, considering all the nonlinear factors and solving the more accurate deflection curve of the telescopic arm.

\section{TELESCOPIC BOOM DEFLECTION EQUATION ESTABLISHED}

\section{A. Flexure Equation of Variable Cross Section Extension Beam}

Telescopic boom in the luffing plane can be regarded as a simply supported outrigger. Its flexural analysis is carried out in the luffing plane ${ }^{[5]}$. In this paper, a typical five-arms telescopic boom is taken as the research object, as Figure I shows. The hinge point at the bottom of the telescopic boom is set as the origin of the coordinate system, and the axis direction of the telescopic arm before deformation is the $\mathrm{x}$-axis, and the $\mathrm{x}$-axis square along the arm end. The $\mathrm{y}$-axis is in the luffing plane and is perpendicular to the $\mathrm{x}$-axis.

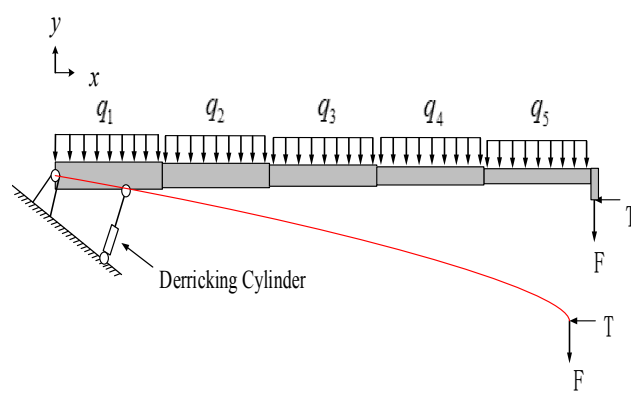

FIGURE I. MODEL OF THE TELESCOPIC BOOM

In the pure bending problem, the approximate differential equation of the flexure curve is ${ }^{[6,7]}$ :

$$
\frac{d^{2} w}{d x^{2}}=\frac{M}{E I}
$$

Formula (1) is suitable for small deformation. For large deformation, using formula (1) will make larger error in calculation, which requires a more accurate formula, as shown in equation (2):

$$
\frac{\frac{d^{2} w}{d x^{2}}}{\left[1+\left(\frac{d w}{d x}\right)^{2}\right]^{\frac{3}{2}}}=\frac{M}{E I}
$$

Applying Eq. (2) to solve the bending deformation of 
telescopic boom, the corresponding deflection curve equation is obtained ${ }^{[6]}$ :

$$
\frac{\frac{d^{2} w}{d x^{2}}}{\left[1+\left(\frac{d w}{d x}\right)^{2}\right]^{\frac{3}{2}}}=\frac{M\left(x, F, T, q_{i}\right)}{E I_{i}}(i=1,2,3,4,5)
$$

In the formula:

$\mathrm{M}\left(\mathrm{x}, \mathrm{F}, \mathrm{T}, \mathrm{q}_{\mathrm{i}}\right)$ _ bending moment at a certain position on the arm, it is a function;

$\mathrm{q}_{\mathrm{i}}$ - each section of the arm to withstand the horizontal uniform load line density, which is the weight of the arm in the horizontal component of the force generated;

E_—metal elastic modulus;

$I_{i}-$ the moment of inertia.

\section{B. Calculation of First-order Flexing Curve}

If we consider only the impact of lateral force, which means calculating the first-order deflection curve, the simplified model of telescopic boom at this time is shown in Figure II.

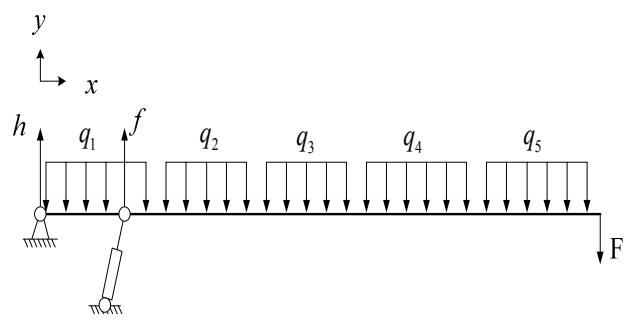

FIGURE II. FORCE DIAGRAM EXCLUDE AXIAL FORCE

The $h$ and $f$ are reaction forces. Its calculation formula can be derived as follows:

$$
\left\{\begin{array}{c}
f=\frac{1}{d_{0}} \mathbf{d} \cdot \mathbf{d}^{T}\left[\begin{array}{rrrrr}
\frac{1}{2} & 1 & 1 & 1 & 1 \\
& \frac{1}{2} & 1 & 1 & 1 \\
& & \frac{1}{2} & 1 & 1 \\
& & & \frac{1}{2} & 1 \\
& & & \frac{1}{2}
\end{array}\right] \cdot \mathbf{q}+\frac{l}{d_{0}} F \\
h=\mathbf{d}^{T} \cdot \mathbf{q}-f-\frac{l-d_{0}}{d_{0}} F
\end{array}\right.
$$

In the formula:

$\mathrm{d}_{0} \_$the distance between two hinges;

$\mathbf{d}=\left[\begin{array}{lllll}d_{1} & d_{2} & d_{3} & d_{4} & d_{5}\end{array}\right]^{T}$ - the extension of each arm from bottom to top;

$\mathbf{q}=\left[\begin{array}{lllll}q_{1} & q_{2} & q_{3} & q_{4} & q_{5}\end{array}\right]^{T} \longrightarrow$ uniform load density generated by arm self weight;
1— telescopic total length.

Regardless of arm weight, the first-order moment is calculated as follows:

$$
M(x)=\left\{\begin{array}{l}
\frac{l-d_{0}}{d_{0}} F \cdot x, x<d \\
(l-x) F, d \leq x \leq l
\end{array} .\right.
$$

Considering the effect of uniform load generated by arm weight, a complete formula of first-order bending moment is obtained:

$$
M_{1}(x)=\left\{\begin{array}{c}
\frac{l-d_{0}}{d_{0}} \cdot F \cdot x+h x-U_{0}, 0<x<d_{0} \\
F \cdot(l-x)-U_{1}, d_{0} \leq x<d_{1} \\
F \cdot(l-x)-U_{2}, d_{1} \leq x<\left(d_{1}+d_{2}\right) \\
F \cdot(l-x)-U_{3},\left(d_{1}+d_{2}\right) \leq x<\left(d_{1}+d_{2}+d_{3}\right) \\
F \cdot(l-x)-U_{4},\left(d_{1}+d_{2}+d_{3}\right) \leq x<\left(d_{1}+d_{2}+d_{3}+d_{4}\right) \\
F \cdot(l-x)-U_{5},\left(d_{1}+d_{2}+d_{3}+d_{4}\right) \leq x<l
\end{array} .\right.
$$

In the formula:

$U_{0}, U_{1}, U_{2}, U_{3}, U_{4}, U_{5}$ the correction value of the bending moments of each section of the telescopic boom, which can be calculated as follows:

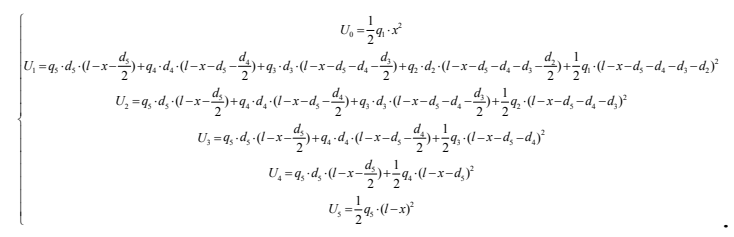

Substituting Eq.(4) and (7) into Eq. (6), the formula for calculating the first moment on the telescopic boom can be obtained. Substituting equation (6) into equation (3) gives the solution of the deflection equation given the values of $\mathrm{E}$ and $\mathrm{I}_{\mathrm{i}}$, where the deflection curve obtained is the first-order deflection curve.

\section{The Length Contraction in Original Axis}

As shown in Figure III, when the arm is not deformed, the position of the arm end is at the point a, and the final equilibrium position of the arm end after the deformation is at the point $\mathrm{b}$. Point $\mathrm{a}$ and point $\mathrm{b}$ in the original axis direction ( $\mathrm{x}$ axis direction) there is deviation, as $\Delta \mathrm{l}$ shown in Figure III.

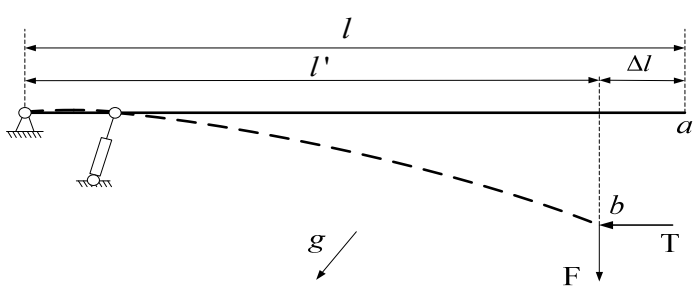

FIGURE III. DIAGRAM THAT SHOWS THE LENGTH CHANGE OF AN OVERHANGING BEAM IN AXIAL DIRECTION

The amount of 1' in Figure III is the length of the arm in 
the $\mathrm{x}$ direction after deformation, which satisfies the relation:

$$
l '+\Delta l=l
$$

The length of the deformed flexure curve can be obtained by integral formula, while the length of the telescopic arm does not change before and after the deformation, so that the formula (9) can be deduced:

$$
\int_{0}^{l^{\prime}} \sqrt{1+w^{\prime 2}} d x=l
$$

Not only the total length of the arm, but also the extension length of each arm is also retracted in the $\mathrm{x}$ direction. The calculation method is also similar to equation (9), which is as Eq. (10):

$$
\int_{0}^{l_{i}^{\prime}} \sqrt{1+w^{\prime 2}} d x=l_{i}
$$

In the formula:

$$
l_{i}=\sum_{1}^{i} d_{i},(i=1,2,3,4)
$$

From Eq. (9) and (10), we can calculate the updated length of each arm and whole arm in the original axial direction after deformation.

\section{Deflection Calculation Considering Second Order Effect}

When the outrigger is subjected to axial force, the axial force tends to generate bending moment, that is, the second-order bending moment. So the deformation of the outrigger becomes larger. The calculation of second-order bending moment is related to the post-deformation equilibrium position and therefore can not be calculated before the deformation, which makes it difficult to obtain the bending line considering the second-order effect.

Now given the initial arm end coordinates as $(l, \delta)$, then the arm at any point of the moment can be calculated according to equation (12).

$$
M=T(\delta-y)+F(l-x) .
$$

Shown in Figure IV, take a small section of the telescopic arm. Its bending moment can be calculated by equation (12).

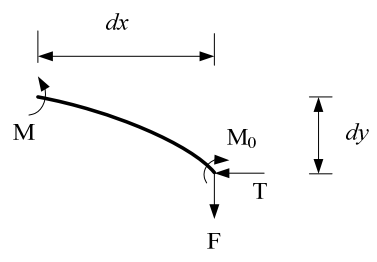

FIGURE IV. FORCE DIAGRAM OF A PUNY SEGMENT OF BOOM
According to the balance of forces, Eq.(13) is available:

$$
M=F d x+T d y+M_{0}+M_{1}(x)=F d x+T d y+T(\delta-y)+F(l-x)+M_{1}(x) .
$$

For the micro-segment arm, its deflection in line with the small deformation assumption, the deflection curve can take Eq. (1) to calculate. The formula (1) seeking a derivative of $\mathrm{x}$, combined with equation (13), the micro-segment deflection of the differential equation can be deduced:

$$
\frac{d^{3} y}{d x^{3}}+\frac{T}{E I} \frac{d y}{d x}+\frac{F}{E I}=0
$$

This is a constant coefficient of non-homogeneous linear differential equations. Its general solution can be obtained as follows:

$$
p=C_{1} \sin \sqrt{\frac{T}{E I}} \cdot x+C_{2} \cos \sqrt{\frac{T}{E I}} \cdot x-\frac{1}{\tan \theta}
$$

Assume the equation of $k=\sqrt{T / E I}$, then the above formula will become the formula as follows:

$$
y=-\frac{1}{k} \cdot C_{1} \cos k \cdot x+\frac{1}{k} \cdot C_{2} \sin k \cdot x-\frac{1}{\tan \theta} x+C_{3}
$$

The boundary conditions expressed by the positions of two hinges are:

$$
\left\{\begin{array}{l}
y(0)=0 \\
y(d)=0
\end{array}\right.
$$

Take the initial arm position of the second derivative as the last boundary conditions, which can be expressed as follows:

$$
y^{\prime \prime}(l)=0
$$

Substituting Eq.(17) and (18) into (16), Eq.(19) can be get:

$$
\left\{\begin{array}{c}
-\frac{1}{k} C_{1}+C_{3}=0 \\
-\frac{1}{k} C_{1} \cdot \cos k d+\frac{1}{k} C_{2} \cdot \sin k d-\frac{d}{\tan \theta}+C_{3}=0 \\
k C_{1} \cdot \cos k l-k C_{2} \cdot \sin k l=0
\end{array}\right.
$$

Solve the above equations, and the following results can be obtained. 


$$
\left\{\begin{array}{l}
C_{1}=\frac{k d \sin k l}{\tan \theta \cdot(\sin k l+\sin k d \cos k l-\sin k l \cos k d)} \\
C_{2}=\frac{k d \cos k l}{\tan \theta \cdot(\sin k l+\sin k d \cos k l-\sin k l \cos k d)} \\
C_{3}=\frac{d \sin k l}{\tan \theta \cdot(\sin k l+\sin k d \cos k l-\sin k l \cos k d)} .
\end{array}\right.
$$

To sum up, considering the second-order effect, the telescopic arm flexural equation is as equation (16). The undetermined coefficient can be obtained using Eq. (20).

\section{Simulink Simulation Model Establishment AND NUMERICAL SOLUTION}

This chapter will use Simulink as a supporting tool, programming corresponding procedures for numerical solution. This study uses the QY25H5 telescopic crane for the data prototype. Its basic parameters are shown in Table I.

\section{TABLE I.BASIC DATA OF THE TELESCOPIC BOOM IN CRANE QY25H5}

\begin{tabular}{|l|l|l|l|}
\hline Iterms & Value & Iterms & Value \\
\hline $\begin{array}{l}\text { Total length of } \\
\text { beam }(l)\end{array}$ & $\begin{array}{l}24293 \\
5\end{array}$ & The density $(\rho)$ & $\begin{array}{l}7.85 \times 10^{-6} \\
{\left[\mathrm{~kg} / \mathrm{mm}^{3}\right]}\end{array}$ \\
\hline $\begin{array}{l}\text { Distance between } \\
\text { hinge points }(d)\end{array}$ & $\begin{array}{l}5270 \\
{[\mathrm{~mm}]}\end{array}$ & $\begin{array}{l}\text { Acceleration of } \\
\text { gravity }(\mathrm{g})\end{array}$ & $9.8\left[\mathrm{~m} / \mathrm{s}^{2}\right]$ \\
\hline $\begin{array}{l}\text { Length of first } \\
\text { arm }\left(l_{1}\right)\end{array}$ & $\begin{array}{l}9172 . \\
5\end{array}$ & $\begin{array}{l}\text { Moment of inertia } \\
\text { of first arm }\left(I_{1}\right)\end{array}$ & $\begin{array}{l}10023073 \\
{[\mathrm{~mm}]}\end{array}$ \\
$\begin{array}{l}\text { Length of second } \\
\text { arm }\left(l_{2}\right)\end{array}$ & $\begin{array}{l}9088 \\
{[\mathrm{~mm}]}\end{array}$ & $\begin{array}{l}\text { Moment of inertia } \\
\text { of second arm }\left(I_{2}\right)\end{array}$ & $\begin{array}{l}82214974 \\
4.2\left[\mathrm{~mm}^{4}\right]\end{array}$ \\
\hline $\begin{array}{l}\text { Length of third } \\
\text { arm }\left(l_{3}\right)\end{array}$ & $\begin{array}{l}8920 \\
{[\mathrm{~mm}]}\end{array}$ & $\begin{array}{l}\text { Moment of inertia } \\
\text { of third arm }\left(I_{3}\right)\end{array}$ & $\begin{array}{l}60481269 \\
7\left[\mathrm{~mm}^{4}\right]\end{array}$ \\
\hline $\begin{array}{l}\text { Length of fourth } \\
\text { arm }\left(l_{4}\right)\end{array}$ & $\begin{array}{l}8720 \\
{[\mathrm{~mm}]}\end{array}$ & $\begin{array}{l}\text { Moment of inertia } \\
\text { of fourth arm }\left(I_{4}\right)\end{array}$ & $\begin{array}{l}39969416 \\
5\left[\mathrm{~mm}^{4}\right]\end{array}$ \\
\hline $\begin{array}{l}\text { Length of fifth } \\
\text { arm }\left(l_{5}\right)\end{array}$ & $\begin{array}{l}8670 \\
{[\mathrm{~mm}]}\end{array}$ & $\begin{array}{l}\text { Moment of inertia } \\
\text { of fifth arm }\left(I_{5}\right)\end{array}$ & $\begin{array}{l}21435953 \\
6\left[\mathrm{~mm}^{4}\right]\end{array}$ \\
\hline
\end{tabular}

One typical condition is chosen to be simulated in this paper. It sets the load as $25 \mathrm{t}$ and telescopic boom elevation as $30^{\circ}$. The Simulink model is compiling according to the calculation method in the first chapter and the data provided in the previous case of this chapter is taken into the program. Then, the curve data can be get and the graph can be drawn, as shown in Figure V.

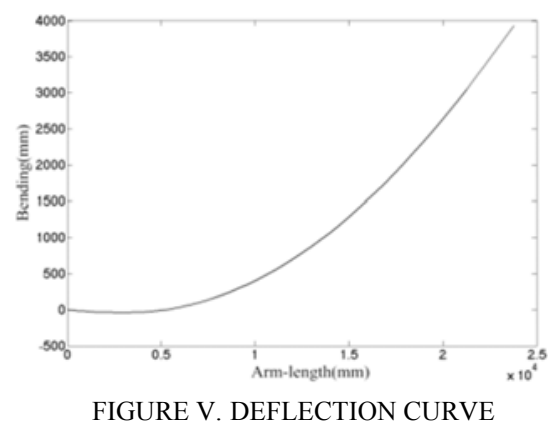

In addition, the study also obtained an approximate curve of deflection for comparison based on the commonly used method of solving approximation curves. The approximate calculation method is completely based on the linear differential equation (1), ignoring the discussion in Section 1.3, which means only one process before the output results. The resulting deflection curve is shown in Figure VI.

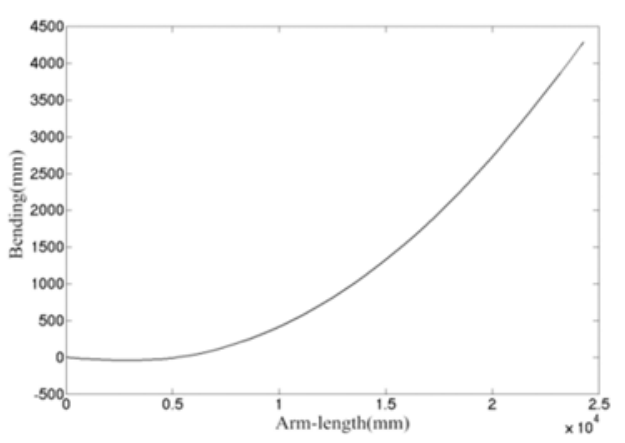

FIGURE VI. APPROXIMATE DEFLECTION CURVE

The results show that the deflection curve of the telescopic arm obtained by the calculation method proposed in this study is smaller than that of the conventional approximate calculation method, and the difference is more significant when the arm length of the telescopic arm is larger.

\section{CONCLUSION}

The method described in this paper for calculating the flexing line of the telescopic boom fully considers all the nonlinear factors that may exist under actual conditions. The nonlinear deflection differential equations used in this paper can greatly improve the accuracy of the calculation compared with the commonly used linear equations, as well as the consideration of the length retraction in original axis and the second-order bending moment. Compared with the general calculation method, the proposed method can solve the flexure curve of the telescopic arm more accurately, and can greatly improve the accuracy of the calculation of the flexile curve of the telescopic arm with large deformation.

\section{ACKNOWLEDGEMENTS}

This research was financially supported by National Natural Science Foundation of China (Grant No.51475068).

\section{REFERENCES}

[1] Lin HUANG. Optimization research of structure for crane telescopic boom [D]. Dalian University of Technology, 2007.

[2] Hui-ming XIE. The recurrence calculation of the deflection curve [J]. Mechanics and Engineering, 2009, 31 (6):74-75.

[3] Wen-jing WANG, Qi-qing YI, Wei HUANG, et al. Deflection curve analysis on cable booms [J]. Chinese Journal of Construction Machinery, 2013, (1):46-50.

[4] Casafont Miquel, Marimon Frederic, Pastor, Maria Magdalena. Calculation of pure distortional elastic buckling loads of members subjected to compression via Calculation of pure distortional elastic buckling loads of members subjected to compression via the finite element method [J]. Thin-Walled Structures, 2009, 47(6-7):701-729.

[5] Cheng QI. Telescopic boom optimization research based on the nonlinear bending [D]. Dalian University of Technology, 2010.

[6] Hong-wen LIU. Mechanics of materials I [M]. Beijing: Higher Education Press, 2011.

[7] Hong-wen LIU. Mechanics of materials II [M]. Beijing: Higher Education Press, 2011. 